\title{
Eliminação de Giardia muris em modelo experimental murino naturalmente infectado:
}

\section{Tratamento complementar}

\author{
Elimination of Giardia muris in naturally infected murine experimental model: Complementary \\ treatment
}

Eliminación de Giardia muris en modelo experimental murino naturalmente infectado:

Tratamiento complementario

Recebido: 09/06/2021 | Revisado: 17/06/2021 | Aceito: 19/06/2021 | Publicado: 02/07/2021

Caroline Rodrigues de Almeida

ORCID: https://orcid.org/0000-0001-9740-4623 Universidade Estadual de Maringá, Brasil

E-mail: caroline_ra@hotmail.com

Renata Coltro Bezagio

ORCID: https://orcid.org/0000-0001-9935-0972 Universidade Estadual de Maringá, Brasil E-mail: renata_coltro@hotmail.com

Cristiane Maria Colli

ORCID: https://orcid.org/0000-0002-6899-7519

Universidade Estadual de Maringá, Brasil

E-mail: cmcolli2@uem.br

Liara Izabela Lopes Romera

ORCID: https://orcid.org/0000-0002-3212-2331 Universidade Estadual de Maringá, Brasil E-mail:liara_romera@hotmail.com

Mônica Lúcia Gomes

ORCID: https://orcid.org/0000-0001-5701-5375

Universidade Estadual de Maringá, Brasil

E-mail: monicaluciagomes@gmail.com

\begin{abstract}
Resumo
Objetivo: Neste estudo foi proposto um tratamento complementar para giardíase murina comparando Chá preto (CPR) (Camellia sinensis) com Metronidazol (MT), Fembendazol (FB) e Metronidazol em associação com Sulfadimetoxina (MtS) em camundongos Swiss machos (30) divididos em seis grupos (CPR, MT, FB/MT, MtS, CPR/MtS e Controle não Tratado - $\mathrm{C}+$ ) com cinco animais cada. Metodologia: $\mathrm{O}$ tratamento foi via intragástrica, por 7 dias 1x/dia e o grupo $\mathrm{C}+$ recebeu apenas água. Os experimentos foram conduzidos de forma cega, controlada, randomizada e repetido uma vez com mesmo número de animais. Parâmetros clínicos (peso, consumo de água, ração e eliminação de excretas) também foram avaliados. Resultados: Os animais dos grupos CPR/MtS e MtS e do grupo CPR apresentaram resultados parasitológicos e molecular negativos para G. muris no $5^{\circ}$ e $7^{\circ}$ dia após início do tratamento, respectivamente. Os animais dos grupos FB/MT, MT e C+ continuaram a eliminar cistos após o término do tratamento. Os animais do grupo $\mathrm{C}+$ apresentaram perda de peso significativa em relação aos animais dos demais grupos e consumiram menor quantidade de ração $(\mathrm{p}=0,0001)$ em relação aos animais dos grupos CPR/MtS, FB/MT e MT. Conclusão: O tratamento complementar com chá preto isolado ou associado ao MtS foi eficaz para eliminar G. muris, sendo uma estratégia promissora para modelo experimental murino. Os animais não tratados que mantiveram alta carga parasitária apresentaram alterações significativas nos parâmetros clínicos, mostrando a importância de eliminar infecção préexistente e aumentar a confiabilidade dos resultados dos experimentos que utilizam esses animais.
\end{abstract}

Palavras-chave: Giardíase; Camellia sinensis; Camundongos.

\begin{abstract}
Objective: This study proposed a complementary treatment for murine giardiasis comparing Black tea (CPR) (Camellia sinensis) with Metronidazole (MT), Fembendazole (FB) and Metronidazole in association with Sulfadimetoxin (Mts) in male Swiss mice (30) divided into six groups (CPR, MT, FB/MT, Mts, CPR/Mts and Untreated Control - C+) with five animals each. Methodology: The treatment was intragastric, for 7 days $1 \mathrm{x} /$ day and group $\mathrm{C}+$ received only water. The experiments were conducted blindly, controlled, randomized, and repeated once with same number of animals. Clinical parameters (weight, water consumption, feed and excreta elimination) were also evaluated. Results: The animals in the CPR/MtS and MtS groups and in the CPR group presented negative parasitological and molecular results for G. muris on the 5th and 7th day after starting treatment, respectively. The animals in groups FB/MT, MT and C+
\end{abstract}


continued to eliminate cysts after the end of treatment. The animals of group $\mathrm{C}+$ presented significant weight loss in relation to the animals of the other groups and consumed less feed $(\mathrm{p}=0.0001)$ in relation to the animals of groups $\mathrm{CPR} / \mathrm{MtS}, \mathrm{FB} / \mathrm{MT}$ and MT. Conclusion: The complementary treatment with black tea alone or associated with MtS was effective to eliminate $G$. muris, being a promising strategy for murine experimental model. The untreated animals that maintained high parasite load showed significant changes in clinical parameters, showing the importance of eliminating pre-existing infection and increasing the reliability of the results of experiments using these animals.

Keywords: Giardiasis; Camellia sinensis; Mice.

\section{Resumen}

Objetivo: En este estudio se propuso un tratamiento complementario para giardiasis murina comparando Té negro (CPR) (Camellia sinensis), Metronidazol (MT), Fembendazol (FB), Metronidazol en asociación con Sulfadimetoxina (Mts) y en ratones suizos machos (30) divididos en seis grupos (CPR, MT, MT/FB, Mts, CPR/Mts y Control no Tratado - $\mathrm{C}+$ ) con cinco animales cada uno. Metodología: El tratamiento fue vía intragástrica, por 7 días 1x/día y el grupo C+ recibió solo agua. Los experimentos fueron conducidos de forma ciega, controlada, aleatoria y repetida una vez con el mismo número de animales. También se evaluaron parámetros clínicos (peso, consumo de agua, alimentación y eliminación de excretas). Resultados: Los animales de los grupos CPR/MtS y MtS y del grupo CPR presentaron resultados parasitológicos y moleculares negativos para G. muris al $5^{\circ}$ y $7^{\circ}$ día de iniciado el tratamiento, respectivamente. Los animales de los grupos FB/MT, MT y $\mathrm{C}+$ siguieron eliminando quistes tras el final del tratamiento. Los animales del grupo $\mathrm{C}+$ presentaron una pérdida de peso significativa en relación con los animales de los otros grupos y consumieron menos alimento $(\mathrm{p}=0,0001)$ en relación con los animales de los grupos CPR/MtS, FB/MT y MT. Conclusión: El tratamiento complementario con chá preto aislado o asociado a MtS fue eficaz para eliminar $G$. muris, siendo una estrategia prometedora para el modelo experimental murino. Los animales no tratados que mantenían una alta carga parasitaria mostraron cambios significativos en los parámetros clínicos, lo que demuestra la importancia de eliminar la infección preexistente y aumenta la fiabilidad de los resultados de los experimentos con estos animales.

Palabras clave: Giardiasis; Camellia sinensis; Ratones.

\section{Introdução}

Os camundongos da espécie Mus musculus são os modelos experimentais mais utilizados em pesquisa científica (Chorilli et al., 2007). No entanto, frequentemente esses animais encontram-se contaminados por inúmeros patógenos como bactérias, fungos, helmintos, protozoários e vírus que podem alterar sua homeostase fisiológica (Pereira, 2002; Chorilli et al., 2007).

Giardia muris é um protozoário flagelado que afeta frequentemente o trato gastrointestinal de roedores provenientes de biotérios de experimentação. Esse parasito pode ocasionar severa resposta inflamatória na mucosa intestinal, perda de peso, distensão abdominal entre outros sinais clínicos (Marques, 2002; Pereira, 2002). Sabe-se que a ingestão mínima de dez cistos pode levar à infecção (Marques, 2002), facilitando a transmissão por meio do contato direto com as próprias fezes podendo assim facilitar a propagação em ambientes fechados como em biotérios.

Inúmeros fármacos estão disponíveis para o tratamento da giardíase, como fembendazol e metronidazol, no entanto falhas terapêuticas são frequentemente relatadas em bezerros, camundongos e seres humanos ( O’Handley et al., 2000; Keith et al., 2003; Alizadeh et al., 2006; Mørch et al., 2008; Brandelli et al., 2009; Leitsch, 2015). Frente a resistência do parasito às terapias convencionais, novas abordagens como uso de plantas medicinais (Bahadur et al., 2015; Fallahi et al., 2016) e o sinergismo entre drogas são alternativas promissoras no tratamento de giardíase murina (Bezagio et al., 2017).

O chá preto (Camellia sinensis) é um dos chás mais consumidos no mundo e uma das suas principais características são as elevadas concentrações de flavonoides ( Li et al., 2013; Hayat et al., 2015). Estudos mostraram que esses compostos têm efeitos benefícios na prevenção da diarreia, controle de problemas digestivos (Naveed et al., 2018) e ações antibacterianas (Boyanova et al., 2015), sem efeitos colaterais aparentes.

Sabendo-se que a infecção por G. muris altera parâmetros clínicos em roedores de laboratório (Bezagio et al., 2017) e causa resposta inflamatória da mucosa intestinal (Venkatesan et al., 1997; Dreesen et al., 2014) é necessário que animais em experimentação estejam livres desse patógeno para que os resultados sejam confiáveis. 
Nesse contexto, foi proposto um tratamento complementar para giardíase murina comparando Chá preto (CPR) (Camellia sinensis) com Metronidazol (MT), Fembendazol (FB) e Metronidazol em associação com Sulfadimetoxina (MtS) em camundongos Swiss naturalmente infectados por G. muris.

\section{Metodologia}

\subsection{Aspectos éticos}

Esse estudo foi aprovado pela Comissão de Ética no Uso de Animais (CEUA) da Universidade Estadual de Maringá, Paraná, Brasil (n 9375170816) e todas as diretrizes da Sociedade Brasileira de Ciência em Animais de Laboratório foram seguidas.

\subsection{Animais}

Camundongos (30) Swiss machos (Mus musculus) não isogênicos, com 21 dias de idade, sem diferença estatística no peso médio dos animais de cada grupo, provenientes do Biotério Central da Universidade Estadual de Maringá (UEM), foram utilizados neste estudo. Os experimentos foram conduzidos de forma cega, controlada, randomizada e repetido uma vez com o mesmo número de animais.

Os animais foram alocados em gaiolas microambientadas Alesco ${ }^{\circledR}$ em biotério climatizado $\left(22,7 \pm 1,2^{\circ} \mathrm{C}\right)$ com ciclo de claro/escuro de 12 horas. Água filtrada e ração (Nuvilab Cr-1, Nuvital ${ }^{\circledR}$ ) foram oferecidas ad libitum e todos os materiais utilizados incluindo o cepilho foram esterilizados em autoclave à $121^{\circ} \mathrm{C}$ por 20 minutos. Antes do início dos experimentos foi feita a adaptação dos animais no Biotério Setorial do Laboratório de Parasitologia Ambiental e de Alimentos da UEM por um período de sete dias.

\subsection{Grupos experimentais, tratamentos e esquemas terapêuticos}

A Tabela 1 mostra os grupos experimentais, os tratamentos e esquemas terapêuticos administrados em camundongos Swiss machos naturalmente infectados por G. muris. Os compostos foram administrados separadamente e em combinação, via intragástrica usando uma cânula de gavagem. A fim de otimizar o tratamento a solubilização dos compostos foi feita com água destilada em um volume de $0,5 \mathrm{~mL}$ administrados uma vez ao dia. No caso de CPR um grama de chá foi diluído em $100 \mathrm{~mL}$ e o volume de $0,5 \mathrm{~mL}$ corresponde a $5 \mathrm{mg}$ de chá preto. Considerando o peso médio dos animais em $25 \mathrm{~g}$ a dose final é de 200 $\mathrm{mg} / \mathrm{Kg}$.

Tabela 1. Grupos experimentais, tratamentos e esquemas terapêuticos administrados em camundongos Swiss machos naturalmente infectados por Giardia muris.

\begin{tabular}{llll}
\hline Grupos & $\begin{array}{l}\text { Node } \\
\text { animais }\end{array}$ & Tratamentos & Esquemas terapêuticos \\
\hline${ }^{1} \mathrm{C}+$ & 5 & Sem tratamento & água filtrada $-1 \times$ dia/7 dias \\
${ }^{2} \mathrm{CPR}$ & 5 & Chá preto (Camellia sinensis) & $200 \mathrm{mg} / \mathrm{kg}-1 \times \mathrm{dia} / 7 \mathrm{dias}$ \\
${ }^{3} \mathrm{MtS}$ & 5 & Metronidazol & $50 \mathrm{mg} / \mathrm{kg}-1 \times \mathrm{dia} / 7 \mathrm{dias}$ \\
& & Sulfadimetoxina & $50 \mathrm{mg} / \mathrm{kg}-1 \times \mathrm{dia} / 7 \mathrm{dias}$ \\
${ }^{4} \mathrm{CPR} / \mathrm{MtS}$ & 5 & Chá preto $($ Camellia sinensis $)$ & $200 \mathrm{mg} / \mathrm{kg}-1 \times \mathrm{dia} / 7 \mathrm{dias}$ \\
& & Metronidazol & $50 \mathrm{mg} / \mathrm{kg}-1 \times \mathrm{dia} / 7 \mathrm{dias}$ \\
& & Sulfadimetoxina & $50 \mathrm{mg} / \mathrm{kg}-1 \times \mathrm{dia} / 7 \mathrm{dias}$ \\
${ }^{5} \mathrm{FB} / \mathrm{MT}$ & 5 & Fembendazol & $50 \mathrm{mg} / \mathrm{kg}-1 \times \mathrm{dia} / 1 \mathrm{dia}$ \\
& 5 & Metronidazol & $500 \mathrm{mg} / \mathrm{kg}-1 \times \mathrm{dia} / 7 \mathrm{dias}$ \\
${ }^{6} \mathrm{MT}$ & 5 & Metronidazol & $500 \mathrm{mg} / \mathrm{kg}-1 \times \mathrm{dia} / 7 \mathrm{dias}$ \\
\hline
\end{tabular}


${ }^{1} \mathrm{C}+\left(\right.$ Grupo controle naturalmente infectado por G. muris e não tratado); ${ }^{2} \mathrm{CPR}$ foi preparado na concentração de $1 \mathrm{~g}$ por $100 \mathrm{~mL}$ de água segundo as recomendações descritas por Tomaszewska et al. (2015); ${ }^{3} \mathrm{MtS}$ (Metronidazol em associação com Sulfadimetoxina)(Andrade, 2002) ${ }^{4}$ Foi administrado Chá preto segundo as concentrações descritas por Tomaszewska et al. (2015) juntamente com Metronidazol segundo a concentração descrita por Bezagio et al. (2017); ${ }^{5} \mathrm{FB} / \mathrm{MT}$ e ${ }^{6} \mathrm{MT}$ foram administrados segundo as recomendações descritas por Bezagio et al. (2017) Fonte: Autores.

Antes de iniciar o tratamento, todos os camundongos foram separados em gaiolas individuais para coleta de fezes e confirmação da infecção. O material fecal $(0,5 \mathrm{~g})$ foi armazenado em frascos de polipropileno, sem conservante. As amostras foram processadas pelo método de Faust et al. (1938) e analisadas microscopicamente. A partir do primeiro dia de tratamento até o décimo dia após o término do tratamento as fezes dos animais foram coletadas diariamente e analisadas pelo método Faust et al. (1938). A quantificação de cistos foi feita pelo método semi-quantitativo estabelecido por Uda-Shimoda et al. (2014). Amostras com menos de 1 cisto/campo microscópico com objetiva de 20x foram consideradas baixa concentração de cistos, 1 2 cistos foram considerados média concentração e mais de 2 cistos/campo foram consideradas alta concentração de cistos. A coleta das amostras e seu processamento foram repetidos ao longo de dezessete dias a partir do início do tratamento.

\subsection{Análise molecular das amostras antes e após tratamento}

Para confirmar a infecção por G. muris e a cura ou permanência da infecção, as fezes de todos os animais foram processadas pelo método de Ritchie (1948) com substituição do formol pela água destilada (Bezagio et al., 2020) durante três momentos: antes do início do tratamento, após o último dia de tratamento ( $8^{\circ}$ dia) e no $10^{\circ}$ dia após o término do tratamento . O DNA de todas as amostras foi extraído com o kit PureLink ${ }^{\circledR}$ PCR Purification (Invitrogen, Carlsbad, CA, EUA), de acordo com as recomendações do fabricante e conforme estabelecido por Uda-Shimoda et al. (2014). O fragmento de 470 pares de base (pb) do gene do RNA ribossômico 18S foi amplificado na reação de PCR padrão usando os primers G18S2 (5' -TGC ACS RSC TGC YAB CC-3') e G18S3(5'-TAG TGY DSY VMV TGY AA-3') com as seguintes reações ( $94^{\circ} \mathrm{C}$ por 2 minutos, então 35 ciclos de $94^{\circ} \mathrm{C}$ por 30 segundos, $55^{\circ} \mathrm{C}$ por 30 segundos e $72^{\circ} \mathrm{C}$ por 1 minuto, finalizando com $55^{\circ} \mathrm{C}$ por 7 minutos) (Monis et al., 1999 ). Os produtos amplificados foram visualizados em gel de poliacrilamida a 4,5\%, revelados com sais de prata, e armazenados digitalmente.

\subsection{Parâmetros Clínicos}

Após a infecção, os animais foram acompanhados por sete dias para a avaliação de parâmetros clínicos quantitativos (peso, ingestão de água e ração e eliminação de excretas). Com auxílio de uma balança semi-analítica cada animal foi pesado diariamente. O consumo diário de ração e quantidade diária de excreta também eram pesadas diariamente e o valor total era dividido pelo número de animais por cada grupo. Essas variáveis foram expressas em grama (g). Com o auxílio de uma proveta graduada a quantidade de água era medida diariamente e expressa em mililitro ( $\mathrm{mL}$ ) e o valor total consumido era dividido pelo número de animais em cada grupo (Bezagio et al., 2017).

\subsection{Eutanásia e avaliação da mucosa intestinal}

Ao $25^{\circ}$ dia do experimento todos os camundongos de cada grupo foram anestesiados em câmara saturada de vapor de halotano (DBC:04596) e após atingirem o plano anestésico foram submetidos a eutanásia por deslocamento crânio-cervical. Foi realizado necropsia assepticamente por meio da abertura da cavidade peritoneal e retirado o intestino delgado de todos os animais. Os intestinos foram lavados com solução salina $0,85 \%$, seccionados longitudinalmente, mergulhados em 25 mL de solução salina 0,85\% e raspado com auxílio de uma lâmina de vidro. Uma porção deste lavado foi analisada microscopicamente, a fim de confirmar a presença e/ou ausência de trofozoítos aderidos na mucosa intestinal. 


\subsection{Critério de Cura}

Os animais que mantiveram resultados negativos pelos métodos parasitológico e molecular, e ausência de trofozoítos na mucosa intestinal no $10^{\circ}$ dia após o término do tratamento foram considerados curados.

\subsection{Análise Estatística}

Os dados obtidos foram digitados em planilha do programa Microsoft Excel 2010 e analisados estatisticamente com o auxílio do Software Statistica Single User versão 13.2. Devido à falta de normalidade nos dados, verificada por meio do teste Shapiro Wilk, optou-se pela utilização de testes não paramétricos para comparar os grupos avaliados por meio do teste Kruskal-Wallis. O nível de confiança adotado nos testes foi de $95 \%$, ou seja, foram consideradas significativas as comparações cujo $\mathrm{p}<0,05$.

\section{Resultados}

No início dos experimentos todos os animais apresentaram resultado parasitológico positivo para G. muris, confirmado pela análise molecular (Figura 1). A eliminação de cistos em todos os animais foi superior a 100 cistos/campo em objetiva microscópica 20X.

Os animais dos grupos MtS e CPR/MtS no $5^{\circ}$ dia de tratamento apresentaram resultado parasitológico negativo para $G$. muris confirmado pelo método molecular (Figura 2) e no $7^{\circ}$ dia os animais do grupo CPR também apresentaram resultado negativo por ambos os métodos (Figura 3). Os animais do grupo FB/MT após último dia de tratamento continuaram a eliminar cistos de G. muris com baixa carga parasitária ( $<1$ cisto/campo) e os animais de MT e C+ com alta carga parasitária $(>100$ cistos/campo) durante todo experimento, resultados confirmados pela detecção do fragmento de $470 \mathrm{pb}$ (Figuras 2 e 3 ).

Figura 1. Amplificação 18S Gene RNA ribossômico de Giardia muris, extraído de amostras de fezes de camundongos naturalmente infectados, visualizado em gel de poliacrilamida 4,5\% revelado com sais de prata. Linha 1: Peso molecular de 100 pb DNA Ladder; Linha 2: Controle positivo (C+) com DNA extraído de trofozoíto de G. muris; Linha 3: Grupo antes do tratamento com Chá preto (CPR); Linha 4: Grupo antes do tratamento com Metronidazol em associação com Sulfadimetoxina (MtS); Linha 5: Grupo antes do tratamento com Chá preto e Metronidazol em associação com Sulfadimetoxina (CPR/MtS); Linha 6: Grupo antes do tratamento com Fembendazol e Metronidazol (FB/MT); Linha 7: Grupo antes do tratamento com Metronidazol (MT); Linha 8: Controle Negativo da PCR, todos os reagentes, exceto DNA (BR).

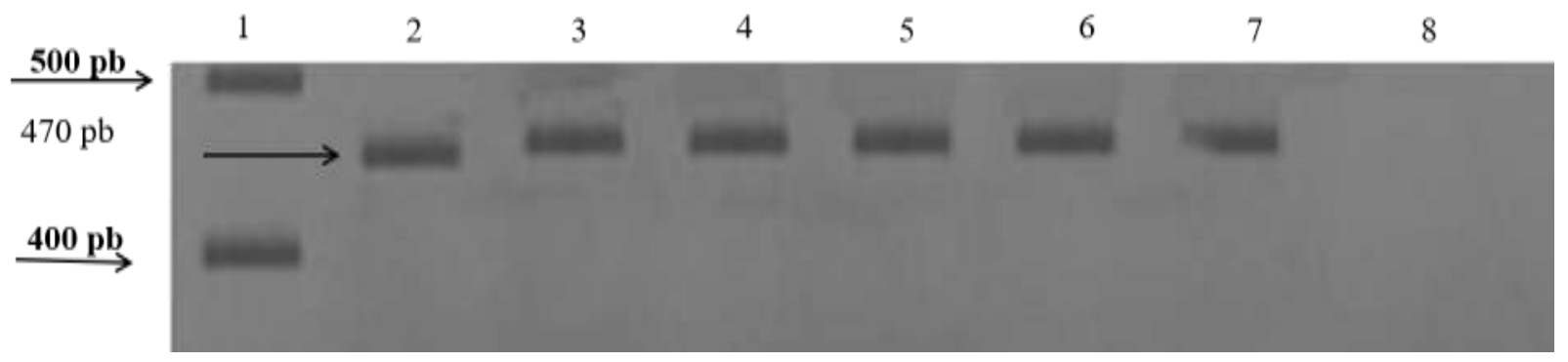

Fonte: Autores. 
Figura 2. Amplificação $18 \mathrm{~S}$ Gene RNA ribossômico de Giardia muris, extraído de amostras de fezes de camundongos naturalmente infectados, coletadas no $5^{\circ}$ dia de tratamento; visualizado em gel de poliacrilamida $4,5 \%$ revelado com sais de prata. Linha 1: Peso molecular de 100 pb DNA Ladder; Linha 2: Controle positivo (C+) com DNA extraído de trofozoíto de G. muris; Linha 3: Grupo tratado com Chá Preto (CPR); Linha 4: Grupo tratado com Metronidazol em associação com Sulfadimetoxina (MtS); Linha 5: Grupo tratado com Chá preto e Metronidazol em associação com Sulfadimetoxina (CPR/MtS); Linha 6: Grupo tratado com Fembendazol e Metronidazol (FB/MT); Linha 7: Grupo tratado com Metronidazol (MT); Linha 8: Controle Negativo da PCR, todos os reagentes, exceto DNA (BR).

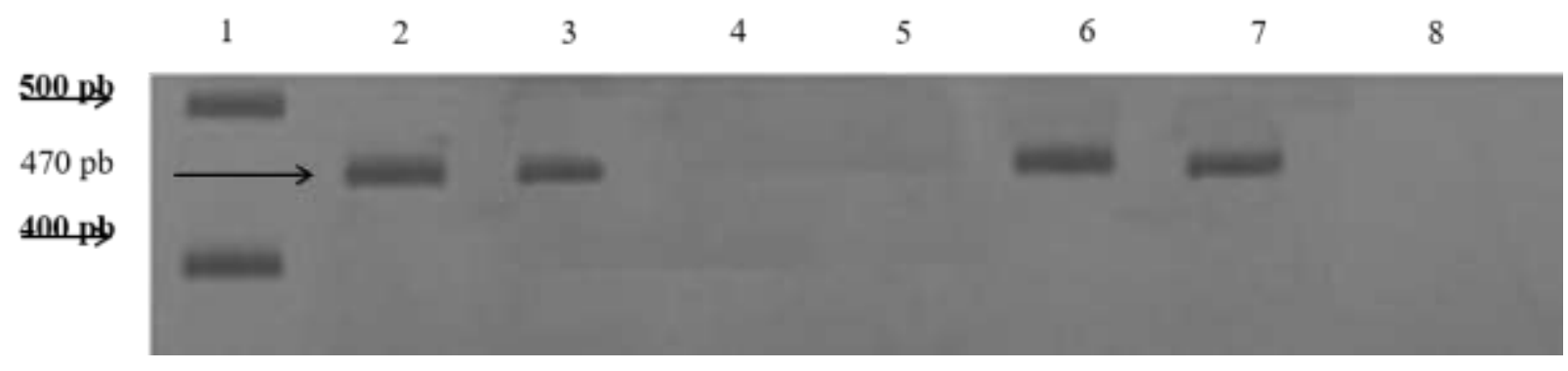

Fonte: Autores.

Figura 3. Amplificação $18 \mathrm{~S}$ Gene RNA ribossômico de Giardia muris, extraído de amostras de fezes de camundongos naturalmente infectados, coletadas no $7^{\circ}$ dia de tratamento; visualizado em gel de poliacrilamida $4,5 \%$ revelado com sais de prata. Linha 1: Peso molecular de 100 pb DNA Ladder; Linha 2: Controle positivo (C+) com DNA extraído de trofozoíto de G. muris; Linha 3: Grupo pós tratamento com chá preto (CPR); Linha 4: Grupo pós tratamento com Metronidazol em associação com Sulfadimetoxina (MtS); Linha 5: Grupo pós tratamento com Chá preto e Metronidazol em associação com Sulfadimetoxina (CPR/MtS); Linha 6: Grupo pós tratamento com Fembendazol e Metronidazol (FB/MT); Linha 7: Grupo pós tratamento com Metronidazol (MT); Linha 8: Controle Negativo da PCR, todos os reagentes, exceto DNA (BR).

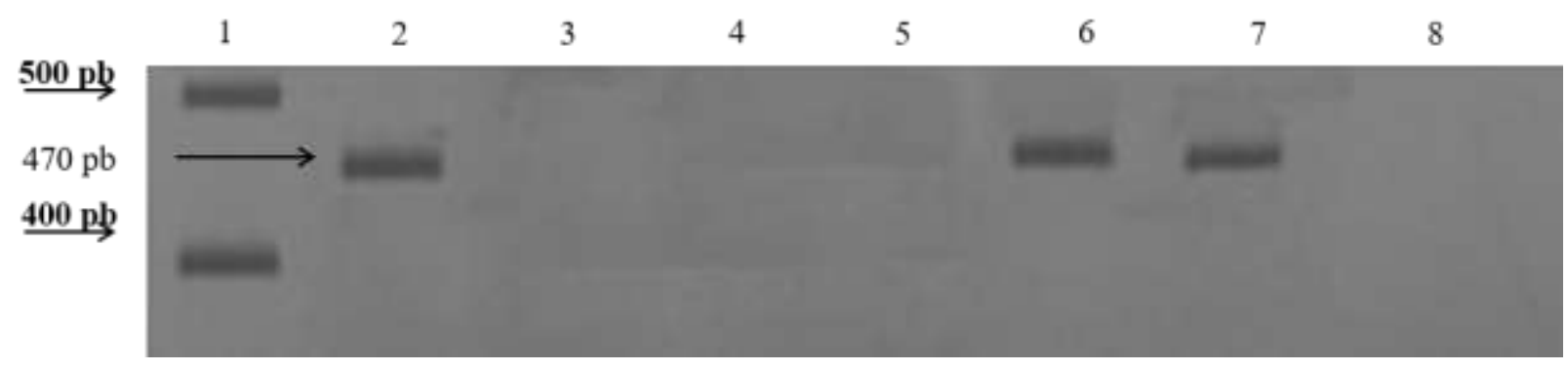

Fonte: Autores.

No $25^{\circ}$ dia do experimento a análise da mucosa intestinal mostrou ausência de trofozoítos nos animais dos grupos CPR, MtS e CPR/MtS, baixa carga parasitária nos animais do grupo FB/MT e alta carga parasitária nos animais dos grupos MT e C+ (Tabela 2). 
Tabela 2. Análise semi-quantitativa da mucosa intestinal de acordo com os grupos analisados.

\begin{tabular}{lcc}
\hline \multicolumn{1}{c}{ Grupos } & $\mathrm{N}^{\circ}$ de animais & *Número de trofozoítos/ Campo microscópio \\
\hline${ }^{1} \mathrm{C}+$ & 5 & $>100$ \\
${ }^{2} \mathrm{CPR}$ & 5 & 0 \\
${ }^{3} \mathrm{MtS}$ & 5 & 0 \\
${ }^{4} \mathrm{CPR} / \mathrm{MtS}$ & 5 & 0 \\
${ }^{5} \mathrm{FB} / \mathrm{MT}$ & 5 & 1 \\
${ }^{6} \mathrm{MT}$ & 5 & $>100$ \\
\hline
\end{tabular}

C+: Controle positivo de G. muris; CPR: Chá preto; MtS: Metronidazol em associação com Sulfadimetoxina; CPR/MtS: Chá preto combinado com Metronidazol em associação com

Sulfadimetoxina; FB/MT: Fembendazol combinado com Metronidazol; MT: Metronidazol.

* Método semi-quantitativo de acordo com os padrões estabelecidos por Uda et al. (2014). Fonte: Autores.

Quanto aos parâmetros clínicos avaliados os animais dos grupos controle positivo $(\mathrm{C}+)$ apresentaram diminuição significativa no consumo de ração em relação aos animais dos grupos CPR/MtS, FB/MT e MT, e redução de peso quando comparado aos animais de todos os grupos que receberam tratamento $(\mathrm{p}<0,0001)$. O grupo $\mathrm{C}+$ também apresentou menor consumo de água comparado com os grupos CPR e CPR/Mts. Outras diferenças entre os grupos são mostradas na Tabela 3.

Tabela 3. Comparação dos parâmetros clínicos quantitativos avaliados de acordo com os grupos analisados.

\begin{tabular}{|c|c|c|c|c|}
\hline *Grupos & Média & Desvio Padrão & $\mathbf{p}$ & Comparações \\
\hline \multicolumn{5}{|l|}{ Ração (g) } \\
\hline $\mathrm{C}+$ & 5,8 & 0,1 & \multirow{6}{*}{$0,0001 * *$} & \multirow{6}{*}{$\begin{array}{l}\mathrm{C}+\text { difere } \mathrm{CPR} / \mathrm{MtS}, \mathrm{FB} / \mathrm{MT}, \mathrm{MT} ; \\
\mathrm{CPR} \text { difere de } \mathrm{CPR} / \mathrm{MtS}, \mathrm{FB} / \mathrm{MT} \text {, MtS e MT; } \\
\mathrm{CPR} / \mathrm{MtS} \text { difere de } \mathrm{MtS}\end{array}$} \\
\hline CPR & 7,7 & 0,2 & & \\
\hline CPR/MtS & 8,5 & 0,1 & & \\
\hline $\mathrm{FB} / \mathrm{MT}$ & 8,3 & 0,2 & & \\
\hline $\mathrm{MtS}$ & 7,9 & 0,1 & & \\
\hline MT & 8,4 & 0,3 & & \\
\hline \multicolumn{5}{|l|}{ Peso (g) } \\
\hline $\mathrm{C}+$ & 13,2 & 0,9 & \multirow{6}{*}{$0,0001 * *$} & \multirow{6}{*}{$\mathrm{C}+$ difere dos demais } \\
\hline CPR & 17,7 & 1,4 & & \\
\hline CPR/MtS & 18,0 & 1,6 & & \\
\hline $\mathrm{FB} / \mathrm{MT}$ & 18,1 & 1,9 & & \\
\hline MtS & 17,2 & 1,9 & & \\
\hline MT & 18,0 & 2,1 & & \\
\hline \multicolumn{5}{|c|}{ Água (mL) } \\
\hline $\mathrm{C}+$ & 8,2 & 0,1 & \multirow{6}{*}{$0,0001 * *$} & \multirow{6}{*}{$\begin{array}{l}\mathrm{C}+\text { difere de CPR e de CPR/MtS; } \\
\text { CPR difere de FB/MT; } \\
\text { CPR/MtS difere dos demais exceto de CPR. }\end{array}$} \\
\hline CPR & 8,7 & 0,1 & & \\
\hline $\mathrm{CPR} / \mathrm{MtS}$ & 8,9 & 0,0 & & \\
\hline $\mathrm{FB} / \mathrm{MT}$ & 8,3 & 0,0 & & \\
\hline $\mathrm{MtS}$ & 8,5 & 0,3 & & \\
\hline MT & 8,5 & 0,0 & & \\
\hline \multicolumn{5}{|c|}{ Excreta (g) } \\
\hline $\mathrm{C}+$ & 2,9 & 0,3 & \multirow{6}{*}{$0,0001 * *$} & \multirow{6}{*}{ MtS difere dos demais } \\
\hline CPR & 2,7 & 0,1 & & \\
\hline CPR/MtS & 2,7 & 0,0 & & \\
\hline $\mathrm{FB} / \mathrm{MT}$ & 2,9 & 0,2 & & \\
\hline $\mathrm{MtS}$ & 2,5 & 0,0 & & \\
\hline MT & 3,1 & 0,4 & & \\
\hline
\end{tabular}

C+: Controle positivo de G. muris; CPR: Chá preto; CPR/MtS: Chá preto combinado com Metronidazol em associação com Sulfadimetoxina; FB/MT: Fembendazol combinado com Metronidazol; MtS: Metronidazol em associação com Sulfadimetoxina; MT: Metronidazol.

*Número de animais utilizados por grupo $(\mathrm{n}=10)$

**Teste Kurskal-Wallis significativo considerando nível de confiança de 95\%. Fonte: Autores.

\section{Discussões}


O presente estudo evidenciou que $200 \mathrm{mg} / \mathrm{Kg}$ de chá preto (Camellia sinensis) utilizado isoladamente, eliminou G. muris de camundongos Swiss no sétimo dia após início do tratamento. Este é o primeiro relato sobre o efeito de chá preto contra esse parasito. Quando esse chá foi associado com Metronidazol/ Sulfadimetoxina (CPR/ MtS) G. muris foi eliminado no quinto dia do tratamento, o mesmo tempo para os animais do grupo MtS.

Um dos chás mais consumidos no mundo (Li et al., 2013; Hayat et al., 2015), o chá preto é rico em flavonóides que têm atividades anti-helmínticas e anti-Giardia (Iqbal et al., 2000; Barbosa et al., 2007; Abdalla et al., 2011). Esses compostos apresentam atividade moduladora da resposta imune intestinal, podendo atuar na redução das enzimas pró-inflamatórias (Martin \& Bolling, 2015), fortalecendo a microbiota intestinal (Oteiza et al., 2018) e favorecendo a barreira intestinal (Oteiza et al., 2018; Pei et al., 2020). O MtS já preconizado no tratamento de caninos e felinos com giardíase causada por Giardia spp entre outros patógenos segundo as recomendações do fabricante, foi também eficaz no tratamento de G. muris.

No grupo CPR (chá preto) a efetividade contra $G$ muris foi evidenciada um pouco mais tarde, no $7^{\circ}$ dia do tratamento. No entanto, o uso desse chá representa um avanço para o tratamento da giardíase murina, por conter substâncias naturais, ter demonstrado ação anti-Giardia e, até o momento, não apresentar efeito colateral aparente. Esse resultado mostra que essa estratégia é promissora e abre perspectivas para investigar a ação desse composto contra a giardíase humana. Por outro lado, o metronidazol, presente nos grupos MtS e CPR/MtS, é eficaz no controle da maioria dos patógenos anaeróbicos e microaerófilos e considerado a droga de escolha para erradicar Giardia (Lalle, 2010; Solaymani-Mohammadi et al., 2010), mas pode apresentar efeitos colaterais indesejáveis, além de aumentar os riscos de carcinogênese e mutagênese (Leitsch, 2019). Em nosso estudo, o metronidazol isoladamente e na dose utilizada não apresentou resultado satisfatório, tendo em vista que não houve diferença na quantidade de parasito eliminado em relação ao grupo que não recebeu nenhum tratamento $(\mathrm{C}+)$, sendo $>100$ cistos/campo microscópico. O Metronidazol só foi eficaz no $5^{\circ}$ dia de tratamento quando associado com a Sulfadimetoxina (MtS). Este composto é um antibiótico de amplo espectro e baixo custo (Bai et al., 2019), mas por sua vez também apresenta potencial carcinogênese, além de gerar impactos ambientais (Bai et al., 2019). Os efeitos adversos desses dois compostos podem comprometer a fisiologia dos animais e consequentemente os resultados de estudos que fizerem o uso dos mesmos.

A utilização do Fembendazol e Metronidazol (FB/MT) no tratamento de G. muris não foi eficaz como preconizado por Bezagio et al. (2017). Os animais ao final do $7^{\circ}$ dia de tratamento, apenas reduziram a carga parasitária para <1 cisto/campo microscópico. A falha terapêutica pode estar associada aos hábitos coprofágicos, muito comum nos roedores, potencializando a infecção e comprometendo o efeito sinérgico das drogas como evidenciado por Bezagio et al. (2017) e a resistência farmacológica de Giardia que ao longo dos anos vem aumentando significativamente, principalmente com relação ao Metronidazol (Muñoz Gutiérrez et al., 2013; Martínez-Espinosa et al., 2015; Rodríguez et al., 2015; Saghaug et al., 2019; Argüello-García et al., 2020).

Uma das limitações desse estudo foi a ausência de um grupo tratado isoladamente com a Sulfadimetoxina, que poderia mostrar melhor a associação do chá preto com todos os compostos aqui testados. Uma das dificuldades de testar esse grupo é pelo fato desse medicamento ser comercial (Giarcid ${ }^{\circledR}$ ) e ter esse composto associado ao Metronidazol. Como no presente estudo, o grupo tratado com Metronidazol não mostrou resultado satisfatório permanecendo com a mesma carga parasitária do grupo controle não tratado, podemos deduzir que nessa associação Sulfadimetoxina e Metronidazol a ação contra $G$. muris deve estar mais relacionada com a Sulfadimetoxina. Outra limitação é a ausência de um grupo chá preto associado ao Metronidazol, mas pelo mesmo motivo acima descrito em relação ao MT e pela ação eficaz do chá preto no grupo CPR, mesmo sendo necessário um período um pouco mais longo de tratamento, acreditamos que essa associação poderia não fazer uma diferença a ser pontuada e ainda propondo um composto como o Metronidazol com sabido efeitos adversos como relatado anteriormente.

A análise dos parâmetros clínicos, mostra a importância do presente estudo em buscar tratamento complementar para eliminar a presença de patógenos no trato intestinal de modelos experimentais. Os animais infectados e não tratados apresentaram alterações importantes em três dos quatro parâmetros avaliados. De um modo geral, os animais que permaneceram infectados 
no grupo C+, com alta carga parasitária, tiveram diminuição no consumo de ração, água e peso em relação aos grupos que receberam tratamento, com diferenças significativas em maior número de parâmetros quando CPR e MtS foram utilizados isoladamente ou associados. A adesão dos trofozoítos que envolvem a mucosa intestinal, principalmente em alta carga parasitária, acabam lesando as microvilosidades, dificultando a absorção de glicose e eletrólitos (Cotton et al., 2011) e ocasionando a perda de peso, o que influencia o crescimento, sobrevivência e altera a homeostase fisiológica do animal ( Pereira, 2002; Chorilli et al., 2007).

\section{Considerações Finais}

O chá preto elimina G. muris de modelo experimental murino. Um maior período de tempo foi requerido (7 dias) quando utilizado isoladamente, mas o tratamento se mostra promissor e seguro por ser a base de produto natural que, até o momento, não apresenta efeito colateral aparente. A associação com MtS reduz o tempo para 5 dias, mas aumenta as chances de ocorrer efeitos adversos por conter os fármacos Metronidazol e Sulfadimetoxina. Houve alterações significativas nos parâmetros clínicos nos animais não tratados em relação aos tratados, mostrando a importância de eliminar o parasito e propor um tratamento complementar que não comprometa a fisiologia de animais utilizados em experimentação.

\section{Agradecimentos}

O presente trabalho foi realizado com apoio da Coordenação de Aperfeiçoamento de Pessoal de Nível Superior - Brasil (CAPES) - Código de Financiamento 001.

\section{Referências}

Alizadeh, A., Ranjbar, M., Kashani, K. M., Taheri, M. M., \& Bodaghi, M. (2006). Albendazole versus metronidazole in the treatment of patients with giardiasis in the Islamic Republic of Iran. Eastern Mediterranean Health Journal = La Revue de Sante de La Mediterranee Orientale = Al-Majallah Al-Sihhiyah Li-Sharq Al-Mutawassit, 12(5), 548-554. http://europepmc.org/abstract/MED/17333792

Andrade, S. F. (2002). Manual de Terapêutica Veterinária (2ºd). Rocca.

Argüello-García, R., Leitsch, D., Skinner-Adams, T., \& Ortega-Pierres, M. G. (2020). Chapter Six - Drug resistance in Giardia: Mechanisms and alternative treatments for Giardiasis. In M. G. B. T.-A. in P. Ortega-Pierres (Org.), Giardia and Giardiasis, Part B (Vol. 107, p. 201-282). Academic Press. https://doi.org/https://doi.org/10.1016/bs.apar.2019.11.003

Bahadur, V., Mastronicola, D., Singh, A. K., Tiwari, H. K., Pucillo, L. P., Sarti, P., Singh, B. K., \& Giuffrè, A. (2015). Antigiardial activity of novel triazolylquinolone-based chalcone derivatives: when oxygen makes the difference. Frontiers in Microbiology, 6, 256. https://doi.org/10.3389/fmicb.2015.00256 Bai, Z., Chen, Y., Li, F., Zhou, Y., Yin, H., \& Ai, S. (2019). Electrochemical aptasensor for sulfadimethoxine detection based on the triggered cleavage activity of nuclease P1 by aptamer-target complex. Talanta, 204, 409-414. https://doi.org/10.1016/j.talanta.2019.06.035

Barbosa, E., Calzada, F., \& Campos, R. (2007). In vivo antigiardial activity of three flavonoids isolated of some medicinal plants used in Mexican traditional medicine for the treatment of diarrhea. Journal of Ethnopharmacology, 109(3), 552-554. https://doi.org/10.1016/j.jep.2006.09.009

Bezagio, R. C., Colli, C. M., Romera, L. I. L., de Almeida, C. R., Ferreira, É. C., Mattia, S., \& Gomes, M. L. (2020). Improvement in cyst recovery and molecular detection of Giardia duodenalis from stool samples. Molecular Biology Reports, 47(2), 1233-1239. https://doi.org/10.1007/s11033-019-05224-5

Bezagio, R. C., Colli, C. M., Romera, L. I. L., Ferreira, É. C., Falavigna-Guilherme, A. L., \& Gomes, M. L. (2017). Synergistic effects of fenbendazole and metronidazole against Giardia muris in Swiss mice naturally infected. Parasitology Research, 116(3), 939-944. https://doi.org/10.1007/s00436-016-5367-9

Boyanova, L., Ilieva, J., Gergova, G., Vladimirov, B., Nikolov, R., \& Mitov, I. (2015). Honey and green/black tea consumption may reduce the risk of Helicobacter pylori infection. Diagnostic Microbiology and Infectious Disease, 82(1), 85-86. https://doi.org/10.1016/j.diagmicrobio.2015.03.001

Brandelli, C. L. C., Giordani, R. B., De Carli, G. A., \& Tasca, T. (2009). Indigenous traditional medicine: in vitro anti-giardial activity of plants used in the treatment of diarrhea. Parasitology Research, 104(6), 1345-1349. https://doi.org/10.1007/s00436-009-1330-3

Chorilli, M., Michelin, D. C., \& Salgado, H. R. . (2007). Animais de laboratório: o camundongo. Revista de Ciências Farmacêuticas Básica e Aplicada, 28(1), 11-23. http://serv-bib.fcfar.unesp.br/seer/index.php/Cien_Farm/article/viewArticle/340

Cotton, J. A., Beatty, J. K., \& Buret, A. G. (2011). Host parasite interactions and pathophysiology in Giardia infections. International Journal for Parasitology, 41(9), 925-933. https://doi.org/10.1016/j.ijpara.2011.05.002

Dreesen, L., De Bosscher, K., Grit, G., Staels, B., Lubberts, E., Bauge, E., \& Geldhof, P. (2014). Giardia muris infection in mice is associated with a protective interleukin 17A response and induction of peroxisome proliferator-activated receptor alpha. Infection and Immunity, 82(8), 3333-3340. https://doi.org/10.1128/IAI.01536-14 
Fallahi, S., Rostami, A., Delfan, B., Pournia, Y., \& Rashidipour, M. (2016). Effect of olive leaf, Satureja khuzestanica, and Allium sativum extracts on Giardia lamblia cysts compared with metronidazole in vitro. Journal of Parasitic Diseases, 40(4), 1204-1209. https://doi.org/10.1007/s12639-015-0650-8

Faust, E. C., D’Antoni, J. S., Odom, V., Miller, M. J., Peres, C., Sawitz, W., Thomen, L. F., Tobie, J., \& Walker, J. H. (1938). A Critical Study of Clinical Laboratory Technics for the Diagnosis of Protozoan Cysts and Helminth Eggs in Feces: I. Preliminary Communication. The American Journal of Tropical Medicine, s1-18(2), 169-183. https://doi.org/10.4269/ajtmh.1938.s1-18.169

Hayat, K., Iqbal, H., Malik, U., Bilal, U., \& Mushtaq, S. (2015). Tea and Its Consumption: Benefits and Risks. Critical Reviews in Food Science and Nutrition, 55(7), 939-954. https://doi.org/10.1080/10408398.2012.678949

Keith, C. L., Radecki, S. V, \& Lappin, M. R. (2003). Evaluation of fenbendazole for treatment of Giardia infection in cats concurrently infected with Cryptosporidium parvum. American Journal of Veterinary Research, 64(8), 1027-1029. https://doi.org/10.2460/ajvr.2003.64.1027

Lalle, M. (2010). Giardiasis in the post genomic era: treatment, drug resistance and novel therapeutic perspectives. Infectious Disorders Drug Targets, 10(4), 283-294. https://doi.org/10.2174/187152610791591610

Leitsch, D. (2015). Drug Resistance in the Microaerophilic Parasite Giardia lamblia. Current Tropical Medicine Reports, 2(3), 128-135. https://doi.org/10.1007/s40475-015-0051-1

Leitsch, D. (2019). A review on metronidazole: an old warhorse in antimicrobial chemotherapy. Parasitology, 146(9), 1167-1178. https://doi.org/10.1017/S0031182017002025

Li, S., Lo, C.-Y., Pan, M.-H., Lai, C.-S., \& Ho, C.-T. (2013). Black tea: chemical analysis and stability. Food \& Function, 4(1), 10-18. https://doi.org/10.1039/c2fo30093a

Marques, M. A. P. (2002). Controle Parasitológico. In A. Andrade, S. C. Pinto, \& R. S. de Oliveira (Orgs.), Animais de laboratório: criação e experimentação (p. 303-315). Fiocruz.

Martin, D. A., \& Bolling, B. W. (2015). A review of the efficacy of dietary polyphenols in experimental models of inflammatory bowel diseases. Food \& Function, 6(6), 1773-1786. https://doi.org/10.1039/C5FO00202H

Martínez-Espinosa, R., Argüello-García, R., Saavedra, E., \& Ortega-Pierres, G. (2015). Albendazole induces oxidative stress and DNA damage in the parasitic protozoan Giardia duodenalis. Frontiers in Microbiology, 6, 800. https://doi.org/10.3389/fmicb.2015.00800

Monis, P. T., Andrews, R. H., Mayrhofer, G., \& Ey, P. L. (1999). Molecular systematics of the parasitic protozoan Giardia intestinalis. Molecular Biology and Evolution, 16(9), 1135-1144. https://doi.org/10.1093/oxfordjournals.molbev.a026204

Mørch, K., Hanevik, K., Robertson, L. J., Strand, E. A., \& Langeland, N. (2008). Treatment-ladder and genetic characterisation of parasites in refractory giardiasis after an outbreak in Norway. The Journal of Infection, 56(4), 268-273. https://doi.org/10.1016/j.jinf.2008.01.013

Naveed, M., BiBi, J., Kamboh, A. A., Suheryani, I., Kakar, I., Fazlani, S. A., FangFang, X., Kalhoro, S. A., Yunjuan, L., Kakar, M. U., Abd El-Hack, M. E., Noreldin, A. E., Zhixiang, S., LiXia, C., \& XiaoHui, Z. (2018). Pharmacological values and therapeutic properties of black tea (Camellia sinensis): A comprehensive overview. Biomedicine \& Pharmacotherapy, 100, 521-531. https://doi.org/10.1016/j.biopha.2018.02.048

O’Handley, R. M., Cockwill, C., Jelinski, M., McAllister, T. A., \& Olson, M. E. (2000). Effects of repeat fenbendazole treatment in dairy calves with giardiosis on cyst excretion, clinical signs and production. Veterinary Parasitology, 89(3), 209-218. https://doi.org/10.1016/s0304-4017(00)00200-4

Oteiza, P. I., Fraga, C. G., Mills, D. A., \& Taft, D. H. (2018). Flavonoids and the gastrointestinal tract: Local and systemic effects. Molecular Aspects of Medicine, 61, 41-49. https://doi.org/10.1016/j.mam.2018.01.001

Pei, R., Liu, X., \& Bolling, B. (2020). Flavonoids and gut health. Current Opinion in Biotechnology, 61, 153-159. https://doi.org/10.1016/j.copbio.2019.12.018

Pereira, A. M. (2002). Principais doenças dos camundongos, ratos e hamsters. In A. Andrade, S. C. Pinto, \& R. S. de Oliveira (Orgs.), Animais de laboratório: criação e experimentação (p. 127-137). Fiocruz.

Ritchie, L. S. (1948). An ether sedimentation technique for routine stool examinations. Bulletin of the U.S. Army Medical Department. United States. Army. Medical Department, 8(4), 326. http://www.ncbi.nlm.nih.gov/pubmed/18911509

Solaymani-Mohammadi, S., Genkinger, J. M., Loffredo, C. A., \& Singer, S. M. (2010). A meta-analysis of the effectiveness of albendazole compared with metronidazole as treatments for infections with Giardia duodenalis. PLoS Neglected Tropical Diseases, 4(5), e682. https://doi.org/10.1371/journal.pntd.0000682

Tomaszewska, E., Winiarska-Mieczan, A., \& Dobrowolski, P. (2015). Hematological and serum biochemical parameters of blood in adolescent rats and histomorphological changes in the jejunal epithelium and liver after chronic exposure to cadmium and lead in the case of supplementation with green tea vs black, red or white t. Experimental and Toxicologic Pathology, 67(5-6), 331-339. https://doi.org/10.1016/j.etp.2015.02.005

Uda-Shimoda, C. F., Colli, C. M., Pavanelli, M. F., Falavigna-Guilherme, A. L., \& Gomes, M. L. (2014). Simplified protocol for DNA extraction and amplification of 2 molecular markers to detect and type Giardia duodenalis. Diagnostic Microbiology and Infectious Disease, 78(1), 53-58. https://doi.org/10.1016/j.diagmicrobio.2013.09.008

Venkatesan, P., Finch, R. G., \& Wakelin, D. (1997). A comparison of mucosal inflammatory responses to Giardia muris in resistant B10 and susceptible BALB/c mice. Parasite Immunology, 19(3), 137-143. https://doi.org/10.1046/j.1365-3024.1997.d01-189.x 